\title{
Reattachment of Rhegmatogenous Retinal Detachment via Fibrin Tissue Adhesive
}

\author{
Erdinc Aydin ${ }^{1,2}$, Erdem Eris ${ }^{2}$, Levent Kazanci², Osman Murat Uyar ${ }^{3}$ \\ ${ }^{I}$ Department of Ophthalmology, Izmir Katip Celebi University School of Medicine, Izmir, Turkey \\ ${ }^{2}$ Eye Clinic, Ataturk Training and Research Hospital, Izmir Katip Celebi University, Izmir, Turkey \\ ${ }^{3}$ Eye Clinic, Liv Hospital, Istanbul, Turkey
}

\begin{abstract}
Purpose: To manage reattachment of rhegmatogenous retinal detachment using tissue adhesive (fibrin glue) in five patients. Methods: Five eyes of five patients with rhegmatogenous retinal detachment were treated with 23-gauge pars plana vitrectomy and the application of fibrin glue (Tisseel Lyo) into the break under air without laser photocoagulation or cryopexy.

Results: The median age of patients was 64 (range, 46-82) years, and the median duration of symptoms was 15 (range, 7-60) days. Three eyes had inferior and two had superior rhegmatogenous retinal detachments. Successful retinal reattachment was achieved in all cases and maintained during the following 10 to 24 months. The median best-corrected visual acuity improved from 2 / 100 preoperatively to a Snellen visual acuity of 20 / 50 by 6 months postoperatively. No postoperative complications were detected during the follow-up period.

Conclusions: Excellent adhesive effects of fibrin glue with respect to sealing retinal tears with no side effects were seen in our study. With further prospective studies, this technique could be an alternative method to conventional retinopexy.
\end{abstract}

Key Words: Fibrin tissue adhesive, Retinal detachment, Vitrectomy

Rhegmatogenous retinal detachment is the most common form of retinal detachment, occurring in about 6 to 18 in 100,000 people per year [1]. Scleral buckling, pneumatic retinopexy, vitrectomy, or combinations of these techniques have been currently used for treating rhegmatogenous retinal detachment. Following rhegmatogenous retinal detachment surgery with pars plana vitrectomy, the use of gas or silicone oil tamponade is often required to manage retinal and retinopexic stabilization. Gas tamponades

Received: February 21, 2020 Final revision: April 18, 2020 Accepted: April 20, 2020

Corresponding Author: Erdinc Aydin, MD, FICOphth. Eye Clinic, Ataturk Training and Research Hospital, Izmir Katip Celebi University, 35630 Karabaglar, Izmir, Turkey. Tel: 90-232-244-4444, Fax: 90-232243-4848, E-mail: erdinc.aydin@ikcu.edu.tr may result in some complications, such as gas migration, glaucoma, cataracts, light scattering, and vascular occlusions [2]. Silicone oil tamponades may cause cataracts, glaucoma, and band keratopathy [3].

Tissue adhesives are classified as synthetic (n-butyl-2-cyanoacrylate) and biological (fibrin glue). Synthetic (cyanoacrylates) and biological fibrin glues have been used extensively in many surgical procedures for two decades. Cyanoacrylates are preferred for external use in order to prevent foreign body reactions [4]. Fibrin sealant is composed of a two-component material consisting of fibrinogen and thrombin. In the presence of calcium and factor XIII, thrombin converts fibrinogen into stable fibrin. This material was utilized as a hemostat by Bergel in 1909 [5], as an adhesive by Young and Medawar in 1940 [6], and for nerve repair by Matras et al. in 1972 [7]. The Food and 
Drug Administration approved liquid fibrin as a sealant in 1998 [8] and as a fibrin patch in 2010 [9]. It was first introduced to ophthalmology to fixate penetrating corneal grafts in rabbits [10]. Recently, fibrin glue has been used not only in ocular surface procedures but also in scleral fixation of intraocular lenses, surgeries for optic disc pit relevant to macular detachments [11-13], and operations for retina [14-16]. However, these retinal techniques using fibrin glue have not been widely studied.

Our study aimed to evaluate a novel surgical technique involving the use of fibrin glue (tissue adhesive retinopexy) for reattachment of rhegmatogenous retinal detachment without using laser photocoagulation or cryopexy .

\section{Materials and Methods}

Informed consent was obtained from all patients included in the study, and the study was performed in adherence with the tenets of the Declaration of Helsinki with the approval of the institutional review board of Izmir Katip Celebi University (2019-OKAE-1065).

This cross-sectional observational case series was conducted at a single tertiary care referral center from September 2017 to April 2019. The following clinical data were recorded for all patients: best-corrected visual acuity, anterior segment and funduscopic findings, intraocular pressures, fundus photography, and videos. All surgeries were performed under local anesthesia by a single surgeon using a vitrectomy system (Stellaris PC; Bausch \& Lomb Surgical, Aliso Viejo, CA, USA) and a noncontact wide viewing system (EIBOS 2; Haag-Streit AG, Koeniz, Switzerland). A standard 23-gauge meticulous and complete pars plana vitrectomy (PPV) was done, and no vitreous was left adherent at the site of the retinal breaks., fluid/perfluorocarbon air exchange, and four patients had endotamponad. We could not perform laser photocoagulation due to the problem with the laser equipment in the first case and observed the management of retina detachment. We decided to implement the next surgeries without endolaser. Furthermore, no tamponade was used in case 5 .

Fibrin glue (Tisseel Lyo two-component fibrin sealant; Baxter AG, Vienna, Austria) 0.1 to $0.2 \mathrm{~mL}$ was applied to the break-edges under air by Duploject injector system with a 23 -gauge fluid needle. The autologous plasma-thrombin mixture was separately heated to near body
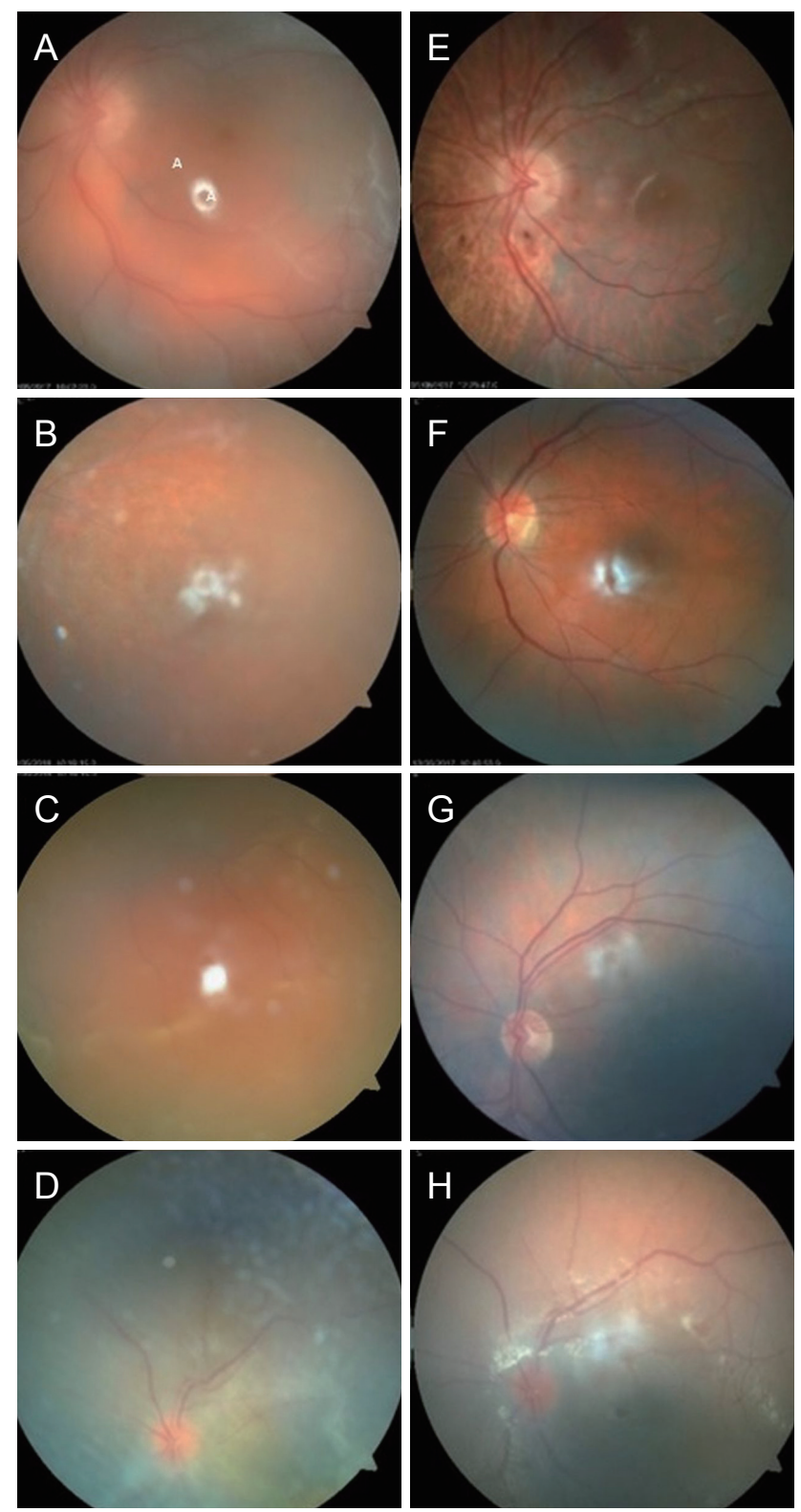

Fig. 1. Fundus images (A-D) showing preoperative retinal detachment and $(\mathrm{E}-\mathrm{H})$ remarking postoperative reattachment of the retina in four cases, respectively.

temperature level (5 minutes) by heating and stirring device (Fibrinotherm, Baxter AG) before injecting it into the patient. After applying fibrin glue under air for 5 minutes, intraocular tamponades were utilized. Of five patients, three patients had silicon oil tamponades, one patient had intraocular gas $(\mathrm{C} 3 \mathrm{~F} 8)$ tamponades, and one patient was left with only air at the end of the operation. The silicon oil tamponades were removed after two months. All patients had reattached retinas following the described procedures. 

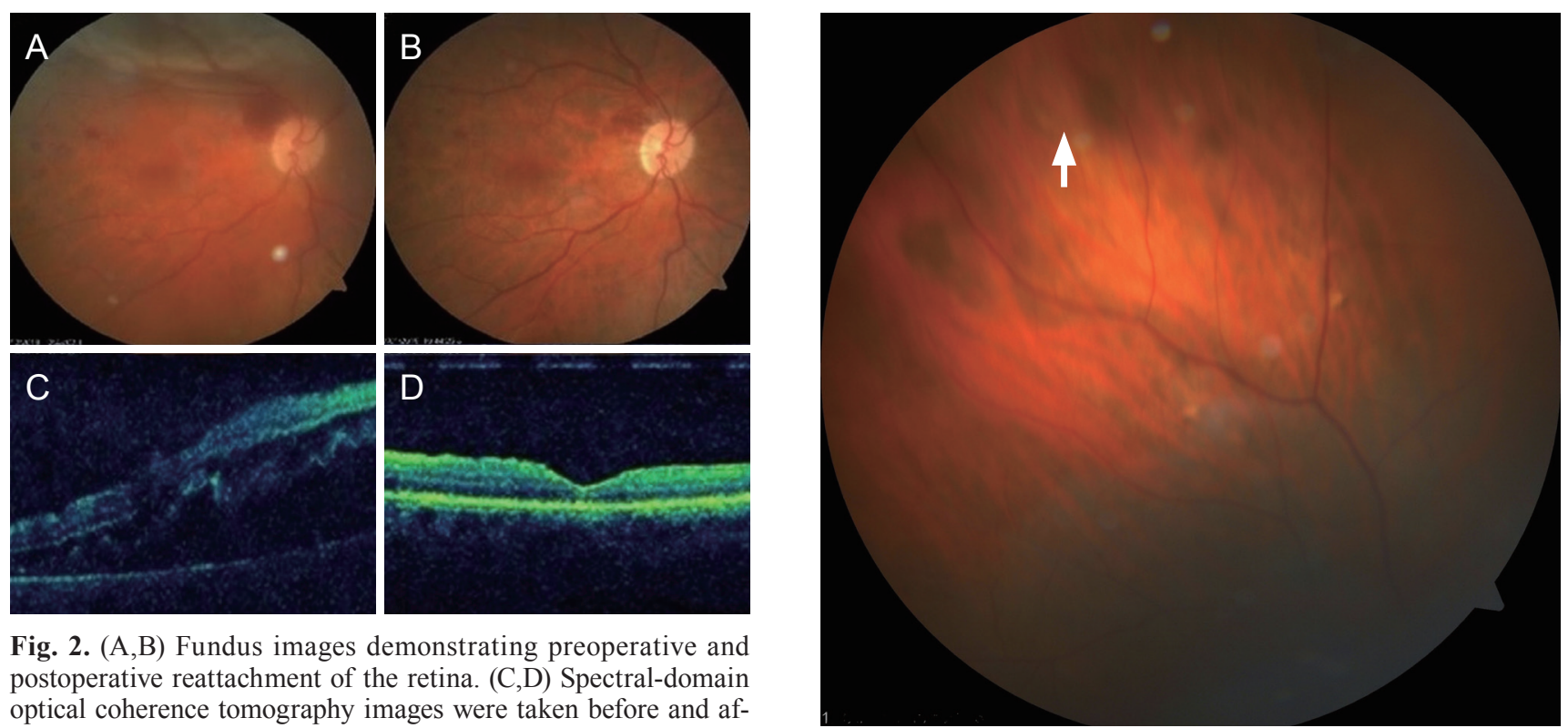

Fig. 2. (A,B) Fundus images demonstrating preoperative and postoperative reattachment of the retina. (C,D) Spectral-domain optical coherence tomography images were taken before and after the application of subretinal fibrin glue in fifth case.

Fig. 3. Fundus picture showing the old retinal tear area (arrow) in the fifth case postoperatively.

Table 1. Patients and clinical data

\begin{tabular}{|c|c|c|c|c|c|c|c|c|c|c|}
\hline $\begin{array}{l}\text { Case } \\
\text { no. }\end{array}$ & $\begin{array}{l}\text { Age } \\
(\mathrm{yr})\end{array}$ & Sex & Eye & Lens & Tamponad & Break / number & $\begin{array}{l}\text { Quadrant } \\
\text { (RD) }\end{array}$ & $\begin{array}{l}\text { Preoperative } \\
\text { (BCVA) }\end{array}$ & $\begin{array}{c}\text { Postoperative } \\
\text { (BCVA) }\end{array}$ & $\begin{array}{c}\text { Follow-up } \\
\text { (mon) }\end{array}$ \\
\hline 1 & 76 & M & $\mathrm{R}$ & PCIOL & Silicon oil & $13: 30 / 1$ & 3 & $2 \mathrm{mfc}$ & 0.3 & 17 \\
\hline 2 & 48 & $\mathrm{~F}$ & $\mathrm{R}$ & Phakic & Silicon oil & $06: 00 / 1$ & 2 & 0.1 & 0.4 & 24 \\
\hline 3 & 68 & M & $\mathrm{L}$ & PCIOL & $\mathrm{C} 3 \mathrm{~F} 8$ & $09: 00-10: 00 / 3$ & 2 & 0.1 & 0.6 & 15 \\
\hline 4 & 46 & $\mathrm{~F}$ & $\mathrm{R}$ & PCIOL & Silicon oil & $06: 00-07: 00 / 3$ & 2 & $\mathrm{HM}$ & 0.1 & 11 \\
\hline 5 & 82 & M & $\mathrm{R}$ & PCIOL & Air & $12: 00 / 1$ & 2 & 0.3 & 0.7 & 10 \\
\hline
\end{tabular}

$\mathrm{RD}=$ retinal detachment; $\mathrm{BCVA}=$ best-corrected visual acuity; $\mathrm{M}=$ male; $\mathrm{R}=$ right $\mathrm{PCIOL}=$ posterior chamber intraocular lens; $\mathrm{F}=$ female; $\mathrm{L}=$ left; $\mathrm{HM}=$ hand motion.

The preoperative (Fig. 1A-1D) and postoperative (Fig. 1E$1 \mathrm{H})$ fundus photographs of four patients are presented. Fundus and spectral-domain optical coherence tomography pictures of patient 5 demonstrated completely restored retinal layers of the macula (Fig. 2A-2D) and the retinal tear area (Fig. 3).

\section{Results}

The median age of patients was 64 (range, 46 to 82) years, and the median duration of symptoms was 15 (range, 7 to 60) days. Three and two eyes had inferior and superior rhegmatogenous retinal detachments, respectively. The medical regimens of all patients were examined at 1-day, 2-weeks, and per month postoperatively. Postoperative evaluations included measurement of the best-corrected visual acuity, intraocular pressure, and fundus photography at all visits when possible. The clinical backgrounds of the patients are presented in Table 1. Successful retinal reattachment was achieved in all cases and maintained during the following 10 to 24 months. The median best-corrected visual acuity improved from 2 / 100 preoperatively to Snellen visual acuity of $20 / 50$ by the 6th month postoperatively. No postoperative complications were detected during follow-up periods. 


\section{Discussion}

In our study, fibrin glue sealed all retinal tear types, and there was no tear recurrence. Retinal breaks are commonly associated with vitreoretinal traction either on an attached flap or on the retina. After removing the vitreoretinal adhesion, retinopexy (scarification of the retina and retina pigment epithelium) can be performed by cryopexia or laser. All retinopexy procedures create tissue destruction and may lead to proliferative vitreoretinopathies in addition to unexpected complications. It is well-known that during vitreoretinal surgery, the application of laser photocoagulation may cause anterior segment complications, such as corneal or lenticular opacification, transient visual loss, foveal photocoagulation, macular edema, hemorrhaging, choroidal effusion, color vision alterations, visual field defects, night vision problems, and hemeralopia [17]. As an alternative to laser photocoagulation, the usage of cryopexy may result in over- or under-freezing, freezing non-target tissues, and tissue cracking [18]. Moreover, cryopexia or laser retinopexy may trigger gliosis, epiretinal membrane formation, proliferative vitreoretinopathy, and tractional retinal detachment. In our study, we used a safe biological agent (Food and Drug Administration approved) for retinopexy, and no adverse effects were seen.

It has also been demonstrated that laser photocoagulation can make the maximum strength of chorioretinal adhesion in the retina until day 5 . The adhesive power of the laser gradually increases and reaches levels that are twice those of normal by 2 to 3 weeks. Laser-related effects are seen earlier and are more definitive than those seen with cryopexy [19,20]. On the other hand, laser photocoagulation requires healthy retinal tissue for light to be absorbed by the pigment in the target tissue. If laser photocoagulation is not possible, retinopexy cannot be performed adequately.

Endotamponade agents are needed to provide surface tension across the retinal breaks that prevent fluid flow into the subretinal space until permanent retinal/choroidal adhesions are repaired by laser photocoagulation or cryopexy. However, silicone oil or gas tamponades cannot adequately close inferior retinal breaks. In this kind of situation, fibrin glue can reveal retinopexy within seconds, so it presumably causes a decrease in rate of surgical failure and also the requirements for intraocular tamponade. In our study, inferior tears were closed without complications and recurrences.
For many years, the plasma thrombin-mixture was applied by many surgical disciplines as a hemostatic agent or tissue glue [21]. Moreover, fibrin has been demonstrated to affect the proliferative characteristics of retina pigment epithelium cells [22]. It has been used in ophthalmology as a sealant to close retinal defects and blepharoplasty [23,24]. Some researchers declared that successful macular hole surgery with an adjunctive agent, as bovine transforming growth factor beta [25,26], is possible. However, Thompson et al. demonstrated that the use of recombinant human transforming growth factor beta had no beneficial effect on anatomical and visual outcomes [27].

Coleman et al. [23] were the first researchers to suggest the use of plasma thrombin-mixture tissue adhesive for closure macular hole related to retinal detachment. de Oliveira et al. [28] declared that four cases of optic disc pit-associated macular detachment managed with PPV, fluid-air exchange, subretinal fluid drainage through the optic disc pit, temporal peripapillary laser, and application of Evicel fibrin sealant (Ethicon, Bridgewater, NJ, USA) over the optic disc head. They suggested that the Evicel fibrin sealant may be considered an adjunctive option in the surgical treatment of optic disc pit-associated maculopathy.

Rodriguez-Torres et al. [29] investigated the biocompatibility of fibrin glue (Beriplast) in experimental vitreoretinal surgery study; there were no significant differences between control and fibrin glue exposed eyes in terms of slit-lamp biomicroscopy, indirect funduscopy, electroretinography, and histological examination.

Wang et al. [15] explored the effects of fibrin glue as an adjuvant that was applied via endolaser in 26 patients with rhegmatogenous retinal detachment during PPV. After the operation, two patients developed epiretinal membranes, and three patients had glaucoma but managed glaucoma with topical anti-glaucomatous drugs. Tyagi and Basu [16] described a technique in which both fibrin glue and endolaser were used without tamponade in five patients with rhegmatogenous retinal detachment. They reported that the retinal reattachment was successfully managed in all patients and no postoperative complications. In our study, we also achieved the reattachment of rhegmatogenous retinal detachment without laser and detected no complications during the follow-up period.

This study was retrospective in nature. The use of non-randomized patients limits the interpretation of the findings. We consider that fibrin glue, firstly keeps the sen- 
sorial retina layer and retina pigment epithelium together stimulating fibrin reaction and proliferation in retina pigment epithelium [22]. Secondly, it also has sealed the surface of the sensorial retina layer as a plug. It blocks any liquid flowing into the subretinal space until the chorioretinal adhesion has formed firmly.

In previous studies using fibrin glue for optic disc pits or retinal detachment, the glue has been demonstrated to stay for 2 weeks $[13,15]$. It is well known that the maximum strength of chorioretinal adhesion has been started at day 5 and reached twice levels within 2 or 3 weeks via laser $[19,20]$. During vitreoretinal surgery, using fibrin glue enables more time for the effective tissue reaction of laser, so the adherence of the retinal layer would be stronger and more confident. In this manner, it would be better to apply laser within 2 weeks in selected cases.

Therefore, fibrin glue may be considered an alternative treatment for the closure of inferior retinal breaks, giant breaks, retinal breaks in high myopia, extensive retinectomies, and retinal sliding during vitreoretinal surgery. Postoperatively, the technique may be more advantageous, especially for preventing collection of subretinal fluid under inferior retinal breaks due to gravity than other methods.

In the near future, we expect that tissue adhesive retinopexy will be useful as an adjunct agent or a substitute for laser photocoagulation or cryopexy during the vitreoretinal surgery. Endotamponade requirements will decrease in the postoperative term. To the best of our knowledge, this study is a new preliminary study concerning the use of fibrin glue in rhegmatogenous retinal detachment without laser photocoagulation or cryopexy application. Further clinical trials are required to define the efficacy of fibrin glue on rhegmatogenous retinal detachment using a larger series with longer follow-up periods.

\section{Conflict of Interest}

No potential conflict of interest relevant to this article was reported.

\section{Acknowledgements}

The authors thank all physicians who participated in each institute in this study. We also would like to thank
Dr. Osman M. Uyar, for providing medical writing assistance.

\section{References}

1. Polkinghorne PJ, Craig JP. Northern New Zealand Rhegmatogenous Retinal Detachment Study: epidemiology and risk factors. Clin Exp Ophthalmol 2004;32:159-63.

2. Kanclerz P, Grzybowski A. Complications associated with the use of expandable gases in vitrectomy. J Ophthalmol 2018;2018:8606494.

3. Antoun J, Azar G, Jabbour E, et al. Vitreoretinal surgery with silicone oil tamponade in primary uncomplicated rhegmatogenous retinal detachment: clinical outcomes and complications. Retina 2016;36:1906-12.

4. Carlson AN, Wilhelmus KR. Giant papillary conjunctivitis associated with cyanoacrylate glue. Am J Ophthalmol 1987;104:437-8.

5. Bergel S. The effect of fibrins. Dtsch Med Wochenschr 1909;35:633-5.

6. Young JZ, Medawar PB. Fibrin suture of peripheral nerves: measurement of the rate of regeneration. Lancet 1940;236: 126-8.

7. Matras H, Dinges HP, Lassmann H, Mamoli B. Suture-free interfascicular nerve transplantation in animal experiments. Wien Med Wochenschr 1972;122:517-23.

8. Los Angeles Times. FDA approves nation's first commercial surgical glue [Internet]. El Segundo: Los Angeles Times; 1998 [cited 2020 Jan 11]. Available from: https:// www.latimes.com/archives/la-xpm-1998-may-02-mn45622-story.html.

9. Fierce Biotech. FDA approves first biodegradable sealant patch for cardiovascular surgery [Internet]. Washington, DC: Fierce Biotech; 2010 [cited 2020 Jan 11]. Available from: https://www.fiercebiotech.com/biotech/fda-approves-first-biodegradable-sealant-patch-for-cardiovascular-surgery.

10. Katzin HM. Aqueous fibrin fixation of corneal transplants in the rabbit. Arch Ophthal 1946;35:415-20.

11. Basu S, Sureka SP, Shanbhag SS, et al. Simple limbal epithelial transplantation: long-term clinical outcomes in 125 cases of unilateral chronic ocular surface burns. Ophthalmology 2016;123:1000-10.

12. Balakrishnan D, Mukundaprasad V, Jalali S, Pappuru RR. A comparative study on surgical outcomes of glued intra- 
ocular lens and sutured scleral fixated intraocular lens implantation. Semin Ophthalmol 2018;33:576-80.

13. Al Sabti K, Kumar N, Chow DR, Kapusta MA. Management of optic disk pit-associated macular detachment with tisseel fibrin sealant. Retin Cases Brief Rep 2008;2:274-7.

14. Blumenkranz MS, Ohana E, Shaikh S, et al. Adjuvant methods in macular hole surgery: intraoperative plasma-thrombin mixture and postoperative fluid-gas exchange. Ophthalmic Surg Lasers 2001;32:198-207.

15. Wang Q, Zhao J, Xu Q, et al. Intraocular application of fibrin glue as an adjunct to pars plana vitrectomy for rhegmatogenous retinal detachment. Retina 2020;40:718-24.

16. Tyagi M, Basu S. Glue-assisted retinopexy for rhegmatogenous retinal detachments (GuARD): a novel surgical technique for closing retinal breaks. Indian J Ophthalmol 2019;67:677-80.

17. Telander DG. Retinal photocoagulation [Internet]. New York: Medscape; 2016 [cited 2020 Jan 11]. Available from: https://emedicine.medscape.com/article/1844294-overview.

18. Dahl AA. Ocular cryotherapy [Internet]. New York: Medscape; 2019 [cited 2020 Jan 11]. Available from: https:// emedicine.medscape.com/article/2049289-overview.

19. Yoon YH, Marmor MF. Rapid enhancement of retinal adhesion by laser photocoagulation. Ophthalmology 1988;95:1385-8.

20. Zauberman H. Tensile strength of chorioretinal lesions produced by photocoagulation, diathermy, and cryopexy. $\mathrm{Br} J$ Ophthalmol 1969;53:749-52.

21. Michel D, Harmand MF. Fibrin seal in wound healing: ef- fect of thrombin and $[\mathrm{Ca} 2+]$ on human skin fibroblast growth and collagen production. J Dermatol Sci 1990;1:32533.

22. Vidaurri-Leal JS, Glaser BM. Effect of fibrin on morphologic characteristics of retinal pigment epithelial cells. Arch Ophthalmol 1984;102:1376-9.

23. Coleman DJ, Lucas BC, Fleischman JA, et al. A biologic tissue adhesive for vitreoretinal surgery. Retina 1988;8:2506.

24. Mandel MA. Closure of blepharoplasty incisions with autologous fibrin glue. Arch Ophthalmol 1990;108:842-4.

25. Glaser BM, Michels RG, Kuppermann BD, et al. Transforming growth factor-beta 2 for the treatment of full-thickness macular holes: a prospective randomized study. Ophthalmology 1992;99:1162-73.

26. Lansing MB, Glaser BM, Liss H, et al. The effect of pars plana vitrectomy and transforming growth factor-beta 2 without epiretinal membrane peeling on full-thickness macular holes. Ophthalmology 1993;100:868-72.

27. Thompson JT, Smiddy WE, Williams GA, et al. Comparison of recombinant transforming growth factor-beta-2 and placebo as an adjunctive agent for macular hole surgery. Ophthalmology 1998;105:700-6.

28. de Oliveira PR, Berger AR, Chow DR. Use of Evicel fibrin sealant in optic disc pit-associated macular detachment. Ophthalmic Surg Lasers Imaging Retina 2017;48:358-63.

29. Rodriguez-Torres EO, Moreno-Paramo D, Baldivieso-Hurtado $\mathrm{O}$, et al. Fibrin glue evaluation like an adjuvant in vitreo-retinal surgery. Indian J Ophthalmol 2013;61:41-2. 